\title{
CORRESPONDENCE
}

\section{Malaria resurgence}

SIR - We are puzzled that our research on malaria resurgence has apparently been misinterpreted and would like to take the opportunity provided by Drs Sharma and Mehrotra to clarify our argument ${ }^{\prime}$.

Most of their evidence has very little bearing on our case. In southern and central India, widespread anopheline resistance to common pesticides developed after 1970 , not during the early and mid-1960s as they seem to suggest (see table). It is also clear that agriculture, not mosquito eradication, is the primary source of pesticide use in these regions.

Comparing annual parasite index figures with agricultural data for the period 1970-76, for example, it is apparent that human infection rates rose most dramatically in districts where local farmers - not public health officials - applied the greatest quantities of insecticides ${ }^{2}$. Moreover, as Sharma and Mehrotra themselves admit "accurate figures for DDT used in agriculture (1960-1972) are not available" - a major weakness in their argument that "use of DDT in agriculture was far less than for public health".

On the contrary, of ficials in FAO and the US Department of Agriculture concur that such figures grossly underestimate the amount of DDT and other chemicals applied by Indian farmers. More important, perhaps, such inaccuracies reflect a significant lapse in reporting during the critical years (1966-72), when high-yielding varieties of rice (needing heavy insecticide use) were introduced into the region. And finally, whereas irrigation schemes may have contributed to the proliferation of mosquitoes, the fact that these mosquitoes quickly became resistant to common pesticides can best be explained by the ways in which farmers used such compounds in newly-irrigated fields.

Thus Sharma and Mehrotra speak more cogently to a different point, namely, that public health authorities in India applied startling quantities of DDT in areas where this compound had long since ceased to be effective against $A$ nopheles vectors. The results of this procedure may be even more serious than they recognize: according to the World Health Organization (WHO), resistance to DDT and related chemicals now affects five (not two) of the seven anopheline species that transmit malaria ${ }^{3}$

Similarly, on the subject of malathion, Sharma and Mehrotra suggest that malaria vectors remain susceptible to this compound in regions where it has not been used for mosquito control but primarily for agricultural purposes. And yet, according to WHO, "A. culicifacies . . . is resistant to

Recent reports of Anopheles resistance to

$\begin{array}{llll}\text { Recent reports of } & \text { Anopheles resistance to commonly used pesticides in India } \\ \text { Date of research } & \text { Compound } & \text { Vector } & \text { Place } \\ 1960 \mathrm{ff} . & \text { DDT, HCH } & \text { A. culicifacies } & \text { Gujarat } \\ 1973 & \text { Malathion } & \text { A. culicifacies } & \text { Gujarat } \\ 1973-78 & \text { DDT, HCH } & \text { A. culicifacies } & \text { Karnataka } \\ 1973-78 & \text { DDT, HCH } & \text { A. fluviatilis } & \text { Karnataka } \\ 1976 & \text { DDT, HCH } & \text { A. stephensi } & \text { Tamil Nadu } \\ 1976-77 & \text { Propoxur } & \text { A. stephensi } & \text { Tamil Nadu } \\ 1978 \mathrm{ff} . & \text { DDT } & \text { A. culicifacies } & \text { Tamil Nadu } \\ \text { ND (post-1976) } & \text { DDT, HCH } & \text { A. subpictus } & \text { Tamil Nadu } \\ \text { ND (pre-1980) } & \text { Fenitrothion } & \text { A. culicifacies } & \text { Not spec. } \\ \text { ND (pre-1980) } & \text { DDT } & \text { A. philippinensis } & \text { Not spec. } \\ \text { ND (pre-1980) } & \text { Malathion, } & \text { A. stephensi } & \text { Not spec. } \\ & \text { Fenitrothion, } & & \end{array}$

DDT, HCH and malathion in 114,33 and 2 districts (one each in Maharashtra and Gujarat) respectively, covering a population of more than $\mathbf{2 5 0}$ million. Resistance to malathion has been detected in other areas one district in Andhra Pradesh and another in Haryana - where the compound is being used for the control of agricultural pests and not in any public health programmes ${ }^{4}$ "'.

Finally, we should add that, unlike Sharma and Mehrotra, we do not possess great faith in the possibility that $A$ nopheles vectors will regain their sensitivity to DDT or other chemicals when these have been withdrawn from the environment for some period of time. Although such events may take place on a limited scale, the weight of entomological evidence speaks for continued or heightened resistance, not "reversion" 5 . Such

considerations are surely the reason WHO has begun to pour its slender resources into studies of vector biology and the development of novel insecticides.

As we mentioned in our article ${ }^{15}$, this quest may also be fruitless: even if these compounds manage to circumvent the largely unknown mechanisms whereby Anopheles mosquitoes detoxify their assailants, they are likely to be so expensive that few governments will be able to afford them. At that point, perhaps, health authorities will give serious attention to what a number of entomologists and other specialists have been saying for some time: that we must develop a rational and comprehensive strategy of ecosystem management which takes into account the need to control both human disease transmission and agricultural pests. These are not separate problems, and the current manner of solving them indiscriminate and self-defeating application of pesticides - will hopefully be assigned a place in our medical history similar to the chapter which now describes how our predecessors removed evil humours from the blood. ROBERT WASSERSTRGM GeGrianne: Chapin

Center for the Social Sciences,

Columbia University, New York, USA

1. Sharma, V. \& Mchrolra, K. Nature 298, 210 (1982). 2. Ahkiar, K. \& L carmunth. A. Malaria Annual Parasite Index Maps of India by Malaria Control Unil Areas. 1965-1976 Open Universily, N(w Delhi. 1979).

3. WHO rech. Rep. Ser. No. 655 (1980)

4. W'HO tech. Rep. Ser. No. $655(1980)$

5. Herath, P. \& Davidson, (i. Bull. Wld Hlih Org. 59, 383-386 (1983).

6. Mojandar Ind J publ. Hith 19 (1975)

7. Majacopal. Ind J. med. Res. $66(1977)$.

Kujagopal. Ind J. med. Res. 72 (1980).

Roy er al Ind J med. Res. 72 (1980).

. Roy et al. Ind. J. med. Res. 72 (1980)

10. Roy et al. Ind. J. med. Res. 67 (1978).

11. Koy et al. Ind. J. med. Res. 68 (1978)

2. Uas \& Rajagopalan, Ind. J. med. Res. 72 (1980)

13. Uas et al. Ind. J. med. Res. $72(1980)$

14. W'HO tech Rep Ser $655(1980)$

15. Chapin, (i. \& Wasserstron, S. Nature 293, 181 (1981)

commonly used pesticides in India

vector

ifacies

A. stephensi

A. culicifacies

A. philippinensis

Not spec.
Sequences on-line

SIR - The recent letter from C. Saccone et al. (Nature I July, p.8) implies that nucleic acid databases are available for European research workers only by mailing of magnetic tapes. Your readers may be interested to know that an extensive nucleic acid sequence database, including the one released by the European Molecular Biology Organization (Nature 15 April, p.596) as well as one developed and maintained by the Los Alamos Scientific Laboratories, can be searched and analysed by direct on-line connection to a Digital Equipment Corporation 2060 computer in Paris, France. This service is provided and maintained by IntelliGenetics, Inc.

Over thirty research groups in six European countries use this service. The databases are in a format compatible with the fastest database search algorithm and the most sophisticated sequence analysis and alignment programs.

ANTHONY H. SLOCUM

IntelliGenetics, Inc.,

Palo Alto, California, USA

\section{Preventing wars}

Sik - The recent letter from the Medical Association for Prevention of War (MAPW) (Nature 9 September, p.102) contains proposals which confuse what international bans and agreements on nuclear weapons can and should do, and what they cannot and should not try to do. I say "contains" because it starts off by suggesting proposals which are reasonable extensions of existing principles with which I have no disagreement. These, however, are used to imply the legitimacy of further ideas of a quite different nature.

The prevention of wars is concerned with many antecedents, some of them being remote from the salient causes of medical injury. The causes of war are separate from the causes of the effects they have on those involved in them. The cause of the growth of an individual tree in a wood is a different thing from the causes of the processes which affect the wood as a whole which may include human economics. MAPW confuses them, mistaking as the same thing the causes of personal loss and the causes of the conflict in which that loss occurs. To remove the latter will remove the former, and is done frequently by the United Nations and the United States.

However, the removal of the former has never led to the removal of the latter.

The main antecedent to war is always the expectation that initiating a military action will lead to gains outweighing the losses incurred in making it. No sane extension of prohibition treaties can be made which allows greater expectation of gain from military action. But this in effect is what MAPW proposes. It is far better to live in a world where there are vast known and undoubted negative expectations of gains from initiating nuclear war but which contains many times the number of warheads potentially to extinguish the human species than to live in one where there are insufficient warheads for that but for which there is a real worthwhile gain for one party to initiate their use.

J.R. SKOYIES

London, UK 